\title{
Congenital CMV Infection and Congenitally Corrected Transposition of Great Artery (CCTGA): an Unusual Association
}

\author{
Kehinde Adebisi* and Benjamin Aubey \\ University of Mississippi Medical Center, USA \\ *Corresponding author: Kehinde Adebisi, University of Mississippi Medical Center, Newborn Medicine Unit, 2500 N. \\ State St. Jackson, MS 39213, USA
}

\section{ARTICLE INFO}

Received: 蔧 July 17, 2021

Published: 㗀 July 23, 2021

\section{ABSTRACT}

Keywords: Infection; Virus; Heart defect; Congenital

Citation: Kehinde Adebisi, Benjamin Aubey. Congenital CMV Infection and Congenitally Corrected Transposition of Great Artery (CCTGA): an Unusual Association. Biomed J Sci \& Tech Res 37(3)-2021. BJSTR. MS.ID.006001.

\section{Introduction}

Congenital Cytomegalovirus (CCMV) infection is one of the most common causes of congenital infections in developed countries with reported incidences varying between $0.15 \%$ and $2.0 \%$. About 40,000 infants are born with congenital CMV infection annually in the United States. Congenital CMV infection is a known to be associated with hearing loss and longterm neurodevelopmental problems. Although neurological manifestations of CCMV infection are well recognized, CCMV infection is rarely associated with congenital heart defects (CHD). Some CHD reported include ventricular septal defects (VSDs), aortic dilatation and TOF, none has reported CCMV being associated with congenitally corrected transposition of a great artery (CCTGA).

\section{Case Presentation}

Our case is a 1-month-old ex-full term asymmetric small for gestational age baby that was born at 39weeks to a 29-yearold mother. Mother had limited prenatal care at our facility (Late transfer from Africa). Pregnancy was complicated by severe preeclampsia and poorly controlled pre gestational DM. Prenatal labs were negative including GBS and Zika virus. Delivery was uncomplicated, APGAR score was 8 and 9 and birth weight of $2200 \mathrm{~g}$ (small for gestational age). Baby was admitted in NICU briefly for poor feeding. Physical exam was significant for small ear, micrognathia, deep seated toenail, hypoplastic nipples and grade 2/6 systolic murmur.

As part of the SGA workup done, brain ultrasound showed grossly normal brain with no intracranial calcification, but salivary CMV PCR was positive [1].

EKG and Echo were done due to presence of murmur; EKG showed Left axis deviation, Left ventricular hypertrophy with repolarization abnormality. Echo showed L- TGA (RA-LV- PALA-RV-AO), Mild Ebstein anomaly of tricuspid valve with trivial insufficiency. Karyotype was 46XY and negative chromosome microarray. Newborn hearing screen (ABR) and New York State Newborn screening were within normal limits. Ophthalmology examination revealed no chorioretinitis. Infectious disease was consulted and recommended treatment, but patient was lost to follow up and came back at 6 weeks. Antiviral treatment was no 
longer recommended at this time since he was more than 1 month old. He was also seen by cardiologist who recommends close follow up and no immediate intervention. Patient has age-appropriate development and no cardiac deterioration on subsequent follow till age $1[2]$.

\section{Discussion}

The effects of congenital CMV infection may vary from a congenital syndrome to an asymptomatic course. Infants that are asymptomatic at birth may still present handicaps at a later age. It is generally accepted that symptoms of congenitally infected children are more severe after primary infection than after recurrent infection. Commonly reported symptoms are Petechiae (50-75\%), Jaundice at birth (40-70\%), Small size for gestational age (40-50\%), Microcephaly (35-50\%) and Sensorineural hearing loss (35\%) among others [3].

CCTGA is a rare congenital heart defect $(0.5-1 \%$ of patient with CHD), also referred to as L- TGA or ventricular inversion. It is due to abnormal looping of the primitive heart. In most cases it is associated with another heart lesion and clinical presentation is dependent on the associated lesions. In patient with no associated

\section{ISSN: 2574-1241}

DOI: 10.26717/BJSTR.2021.37.006001

Kehinde Adebisi. Biomed J Sci \& Tech Res

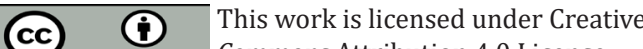
Commons Attribution 4.0 License

Submission Link: https://biomedres.us/submit-manuscript.php lesion, presentation is usually in adulthood with RV dysfunction and heart failure [4].

\section{Conclusion}

We are reporting this case because it is an unusual association with congenital CMV infection, and none has been reported in literature till date. The consequence of CMV can be severe and lifelong so we recommend a high index of suspicion and need for thorough evaluation of any baby suspected, including cardiac evaluation.

\section{References}

1. Michael A, Gaytant G, Ingrid JG, Rours Eric AP, SteegersJochem MD, et al. (2003) Congenital cytomegalovirus infection after recurrent infection: case reports and review of the literature. European journal of pediatrics 162(4): 248-253.

2. David R Fulton, David A Kane (2018) L-transposition of the great arteries.

3. Gail J Demmler Harrison (2019) Congenital cytomegalovirus infection: Clinical features and diagnosis.

4. Nida Manzoor, Aiman Rehan, Manahil Akmal, Tayram B Khalid, Ammarah, Jamal (2019) Congenital Cytomegalovirus Infection and Tetralogy of Fallot: An Unusual Association in a Three-month-old Baby. Cureus 11(6): e4949.

$\begin{array}{ll}\text { BIOMEDICAL } & \text { Assets of Publishing with us } \\ \text { RESEARCHES } & \text { - Global archiving of articles } \\ \text { - Immediate, unrestricted online access }\end{array}$

